\title{
Reply to Letter to the editor regarding "The ZJU index is a powerful index for identifying NAFLD in the general Chinese population"
}

\author{
Linman $\mathrm{Li}^{1}{ }^{\mathbb{C}}$
}

Received: 3 August 2019 / Accepted: 21 September 2019 / Published online: 24 October 2019

(c) Springer-Verlag Italia S.r.l., part of Springer Nature 2019

Dear Dr. Fu,

Thank you for pointing out that the formulas listed in the article entitled "The ZJU index is a powerful index for identifying NAFLD in general Chinese population" [1] were incorrect.

The calculation of VAI value in my paper is based on the formula given in the paper written by Petra et al. [2]. We also have verified the data again which showed that we did calculate the VAI value with the right formula in the paper. Due to errors in editing documents in my paper, the VAI formula given is incorrect and should be corrected as follows: $\mathrm{VAI}=[\mathrm{WC} /(39.68+(1.88 \times \mathrm{BMI}))] \times(\mathrm{TG} / 1.03) \times(1$. $31 / \mathrm{HDL})$ for males; [WC/(36.58+(1.89 $\times \mathrm{BMI}))] \times(\mathrm{TG} / 0.8$ $1) \times(1.52 / \mathrm{HDL})$ for females $[2,3]$.

In addition, you were curious about why it is called as ZJU index. As the authors who created the index did not mention why in their article $[4,5]$, I can only speculate it maybe because the authors developed the ZJU index from "Zhejiang University".

Please accept my apologise again for the mistake and the inconvenience caused.

Wish you a nice day.

Managed by Antonio Secchi.

This reply refers to the article available at https://doi.org/10.1007/ s00592-019-01428-0.

Linman Li

1360896542@qq.com

1 Chongqing, China
Best regards, Linman Li

\section{References}

1. Li L, You W, Ren W (2017) The ZJU index is a powerful index for identifying NAFLD in the general Chinese population. Acta Diabetol 54(10):905-911

2. Petta S, Amato M, Cabibi D et al (2010) Visceral adiposity index is associated with histological findings and high viral load in patients with chronic hepatitis $\mathrm{C}$ due to genotype 1. Hepatology $52: 1543-1552$

3. Amato MC, Giordano C, Galia M et al (2010) Visceral adiposity index: a reliable indicator of visceral fat function associated with cardiometabolic risk. Diabetes Care 33:920-922

4. Wang J, Xu C, Xun Y et al (2015) ZJU index: a novel model for predicting nonalcoholic fatty liver disease in a Chinese population. Sci Rep 5:16494

5. Wang J, Ma L, Chen S et al (2018) Risk for the development of non-alcoholic fatty liver disease: a prospective study. J Gastroenterol Hepatol 33(8):1518-1523

Publisher's Note Springer Nature remains neutral with regard to jurisdictional claims in published maps and institutional affiliations. 